\title{
Perfil: o humanismo secular de Edward Said
}

\author{
${ }^{1}$ Khalid Tailche \\ ${ }^{2}$ Maged El Gebaly
}

Edward Said segue sendo uma inspiração para os críticos do imperialismo passado e presente, e para as lutas por um mundo mais consciente, mais justo e menos violento. Nascido em Jerusalém em 1935, viveu o mandato britânico na Palestina ocupada. Com 12 anos, mudou-se com a família para a cidade do Cairo, no Egito; seu pai, cristão palestino, tinha emigrado para os Estados Unidos em 1911. Emigrou de forma definitiva com sua família para esse país em 1951, após a resolução da ONU de 1947, que dividia Jerusalém em duas partes: árabe e israelense. Com 28 anos, em 1963, torna-se professor da Universidade de Columbia, local em que, em 1968, ocorreram grandes protestos em favor da paz e contra a guerra do Vietnã. Nessa universidade lecionou literatura comparada (inglesa e americana) desde a perspectiva dos estudos culturais. Como todos os árabes engajados, em sua própria terra ou no exílio, sofreu perseguições.

O pós-colonialismo serviu como ponto de partida de Edward Said para ter consciência das representações e dos diferentes modos de percepção utilizados pelo colonizador para controlar os povos colonizados. Para seu amigo antilhano Frantz Fanon ${ }^{3}$ (1925-1961), o fim de colonialismo não

1 Professor e tradutor árabe-inglês. Doutorando em Letras pela Universidade de São Paulo.

2 Professor na Universidade de Ain Shams, Egito. Doutorando em Estudos Comparados de Literaturas de Língua Portuguesa, Universidade de São Paulo.

3 FANON, Frantz. Os condenados da terra. Tradução de José Laurenio de Melo. Rio de Janeiro: Civilização brasileira, 1968. 
representaria somente dimensões políticas e econômicas, mas também psicológicas que afetam a própria formação narrativa das identidades do colonizado. Esta relação entre o ideal colonizador e o real colonizado na tese de doutorado de Said sobre O Coração das trevas ${ }^{4}$ de Joseph Conrad, mostra uma preocupação com os processos narrativos de legitimação do sistema de império do colonizador. Na leitura contrapontual do romance, a imagem das trevas fica associada à imagem revertida do eurocentrismo como luz, projeto civilizador.

Nas suas obras Orientalismo (1978), A questão da Palestina (1979) e Cobrindo o Islã (2007), Said vai desconstruindo o discurso tecido pelos orientalistas europeus e estadunidenses durante os séculos XVIII e XIX, do imaginário deturpado do Outro. Nesse caso o oriental, o árabe e/ou o muçulmano, levou Said a examinar a relação entre o Ocidente e Oriente: os sistemas colonizadores e as culturas colonizadas. Said faz uma crítica contrapontual ao discurso acadêmico colonial eurocêntrico, que generaliza e estereotipa a imagem de Oriente sob o nome de "orientalismo", uma área de estudo que abarca filólogos e historiadores especializados nas línguas orientais e suas letras desde uma ótica colonialista. Ele faz uma crítica contrapontual à linguagem exótica horizontal "orientalista" do romantismo e às descrições naturalistas que continuam vivas hoje nos discursos lineares essencialistas que promovem choque de civilizações, dividindo o mundo em blocos com fronteiras religiosas e raciais rígidas. A genialidade da obra de Said se revela principalmente na sua consciência crítica do Orientalismo que, enquanto se apresentava como um conhecimento esclarecido de pensamento iluminista, tinha ligação direta com as práticas de poder do colonialismo.

A imagem colonialista coloca o Oriente e seus povos como inferiores diante do colonizador. Mais tarde, Said escreveu um artigo intitulado $O$ orientalismo reconsiderado ${ }^{5}$ para deixar claro que sua intenção era desenvolver

CONRAD, Joseph. O coração das trevas. Tradução de Sérgio Flaksman. São Paulo: Companhia das Letras, 2008.

5 SAID, Edward W. O orientalismo reconsiderado. In: Reflexões sobre o exílio e outros ensaios. Trad. Pedro Maia Soares. São Paulo: Companhia das Letras, 2003. pp. $61-78$. 
uma crítica oposicional, que traz para o campo acadêmico um olhar diferenciado de vozes marginalizadas. Segundo o autor, o colonizador criou uma consciência falsa do Oriente, numa tentativa de diferenciação que servia os interesses do colonialismo. Said analisou uma série de discursos literários, políticos e culturais nos quais encontrou um denominador comum: a representação dos povos não europeus como bárbaros.

Em Cultura e Imperialismo (1995), o autor analisa como os propósitos imperialistas influenciaram as grandes narrativas literárias inglesas e francesas e ajudaram a concretizar preconceitos colonialistas defendidos pela política imperialista de países como a Inglaterra, França e Estados Unidos. Para Said, o intelectual especular cria consciência crítica do imperialismo e sua relação com os conflitos e os hibridismos. O imperialismo cultural está prestes a apropriar-se de elementos de culturas periféricas para reutilizá-los a partir das culturas hegemônicas. Objetos da cultura popular passam a ser inseridos numa esfera elitizada de consumo. Nesse sentido, o império é uma relação, formal ou informal, em que um Estado colonial controla a soberania política efetiva de outra sociedade política, e o imperialismo é simplesmente o processo ou a política de estabelecer ou manter um império. Imperialismo significa pensar, colonizar, controlar terras que não são nossas, que estão distantes, que são possuídas e habitadas por outros. Para resistir o imperialismo, emerge uma luta ideológica que tenta restaurar uma comunidade estilhaçada.

Seguindo Giambattista Vico ${ }^{6}$ (1668-1744), Said distingue dois modos da prática literária em relação à tradição: o filiativo, do domínio da natureza, e o modo afiliativo, da sociedade e da cultura. A relação literária filiativa com os cânones tem tendência a ser contestada por relações afiliativas construída pela crítica cultural que considera os textos nos seus universos de produção e recepção e não numa textualidade isolada do seu contexto comunicativo. Nesse sentido, Said aponta a uma crítica secular, que vai como num eterno retorno a

6 VICO, Giambattista. A ciência nova. Tradução de Marco Lucchesi. Rio de Janeiro: Record, 1999. 
um tipo de "poética de persistência" na resistência ao patriarcalismo imperialista.

Said apela à consciência crítica dos que estão fora de lugar, que estão viajando para dentro em outro lugar e em outro contexto, por não estarem em um contexto único, dominado por uma verdade única, em um mundo em que o exílio não tem fronteiras. Em Reflexões sobre o exílio: e outros ensaios, Said conta diferentes pontos na sua trajetória: longe de onde nasceu, o entrelugar ao que pertence lhe possibilita uma crítica ambivalente de diferentes formas de exílio. Said (2003) afirma que "nascemos nele, ou ele nos acontece". Para ele, trata-se de um sofrimento, uma solidão que surge como resultado da fragmentação incurável do ser humano que se separa do seu lar. No exílio, toda a narrativa do triunfo que o homem produz serve como uma maneira de tentar superar este sofrimento. Segundo o crítico palestino, vivemos a era dos exilados que sentem uma necessidade de retomar suas vidas fragmentadas por estarem fora das suas comunidades como foi o caso do filólogo alemão Erich Auerbach (1892-1957), exilado da Alemanha nazista para Istambul, onde escreveu sua Mimesis ${ }^{7}$. Segundo Said, o exílio cria uma solidariedade comunitária exagerada e acaba alimentando paradoxalmente o vínculo afetivo à sua procedência. $\mathrm{O}$ exilado começa a recriação do seu ser no novo entrelugar somente quando consegue reconstruir sua narrativa identitária, não a partir de supostas "origens" estáveis, mas da descontinuidade que caracteriza o exílio. Nesse sentido, o exilado desenvolve uma consciência dialogante para recriar uma subjetividade ativa e não sentir marginalizado.

Said dialoga com o pensamento filosófico político de António Gramsci ${ }^{8}$ (1891-1937), especialmente nas suas palestras Representação do intelectual (2005), nas quais contextualiza como os intelectuais representam a si mesmos e como desempenham a sua função. Said não acreditava na neutralidade política e faz uma abordagem das várias posições ideológicas do intelectual no século XX: de

\footnotetext{
7 AUERBACH, Erich. Mimesis: a representação da realidade na literatura ocidental. Tradução de George Bernard Sperber. São Paulo. Editora Perspectiva, 1976. $8 \quad$ GRAMSCI, Antônio. Os intelectuais e a organização da cultura. Rio de Janeiro: Civilização Brasileira, 1989.
} 
direita, conservador, progressista e até mesmo dos intelectuais cooptados. Said alerta para um tipo de ameaça que paira sobre os intelectuais: o "profissionalismo". O intelectual burocrático, que não sai dos limites aceitos, comercializável, incontroverso e apolítico. Para Said, o intelectual, por ser um sujeito político consciente nas margens do centro, consegue "falar a verdade ao poder" e desmascarar o discurso que vai "culpando a vítima". Os estudos póscoloniais de Fanon e Said e mais tarde de Homi K. Bhabha e Gayatri Spivak dedicaram-se a duas questões principais: a primeira é detectar o passado colonial na cultura, a segunda é entender como essas culturas - e através dos seus intelectuais - posicionam-se em relação a esse passado colonial, no esforço de entender o mundo e contextualizar suas histórias ligadas às memórias da colonização.

Na teoria pós-colonial, procura-se dar voz ao subalterno, aos discursos do neocolonialismo de nossos dias, à reprodução epistemológica dos modelos da colonização, e às relações coloniais entre os conhecimentos, as formas de representação do Outro e a internalização do poder colonizador, por meio da ação cultural crítica na fase pós-independência. A crítica que os estudos culturais levantaram foi proliferando em teorias viajantes em novas dimensões discutindo os novos tipos de colonização, a neocolonização, que não exige uma intervenção militar e que aproveita a globalização de um mundo cada vez mais interconectado e em que as divisões e as fronteiras enfraquecem. À maneira de Michel Foucault (1926-1983), Said dá ênfase à necessidade de desenvolver uma linguagem crítica do eurocentrismo como produto do conhecimento positivista do século XIX. No Humanismo e crítica democrática (2007), Said dialoga com os estudos pós-estruturalistas de Michel Foucault e insiste que o humanismo democrático precisa desenvolver uma crítica oposicional do eurocentrismo na ordem e na genealogia do discurso epistemológico no século XIX. Said vê o humanismo cosmopolita além da sua imagem eurocêntrica ou até imperialista que o acompanhou. Para Said, o humanismo crítico se realiza no autoconhecimento acompanhado pela autocrítica. Para o crítico palestino, o humanismo democrático não parte de uma verdade única que elimina 
diferentes formas de pensar, mas da diversidade entre as culturas, o que não cria conflitos entre as verdades essencializadas diante da crescente complexidade do mundo. Na visão do Said, as culturas podem coexistir não em base de uma essência, mas na forma de um dialogo que procura entender a diversidade humana.

Em Estilo Tardio (2009), livro editado pelos amigos próximos de Edward Said depois da sua morte em 2003, busca revelar a complexidade das variadas manifestações da linguagem humana (pintura, música, poesia, narrativas e filmes) na sua fase tardia de pensamento e de viver sereno, mas muitas vezes com contradições não resolvidas. Said procura entender a existência humana que a morte não consegue apagar através da produção tardia de escritores como Konstantínos Kaváfis (1863-1933), Thomas Mann (1875-1955), Giuseppe Tomasi di Lampedusa (1896-1957), Theodor Adorno (1903-1969) e Jean Genet (1910-1986); compositores como Bach (1685- 1750), Mozart (1756-1791), Beethoven (1770-1827), Wagner (1813- 1883), Arnold Schoenberg (1874-1951) e Richard Strauss (1864-1949); cineastas como Luchino Visconti (1906-1976); e pintores como Rembrandt (1606-1669) e Matisse (1869-1954). Trata-se de um estilo tardio que escolhe a liberdade, não somente do colonizador, mas de tudo que prende o processo de pensamento e de conhecimento. Esta liberdade que a linguagem artística traz abre para nós novos universos. Com isso, a responsabilidade do intelectual - diante da colonização e da injustiça - é a de não perder a noção da arte. Enquanto os conflitos ocorrem, a arte continua. 


\section{Escritório de Edward Said na Universidade de Columbia em Nova York nos Estados Unidos - (Foto de Khalid Tailche, janeiro de 2012)}

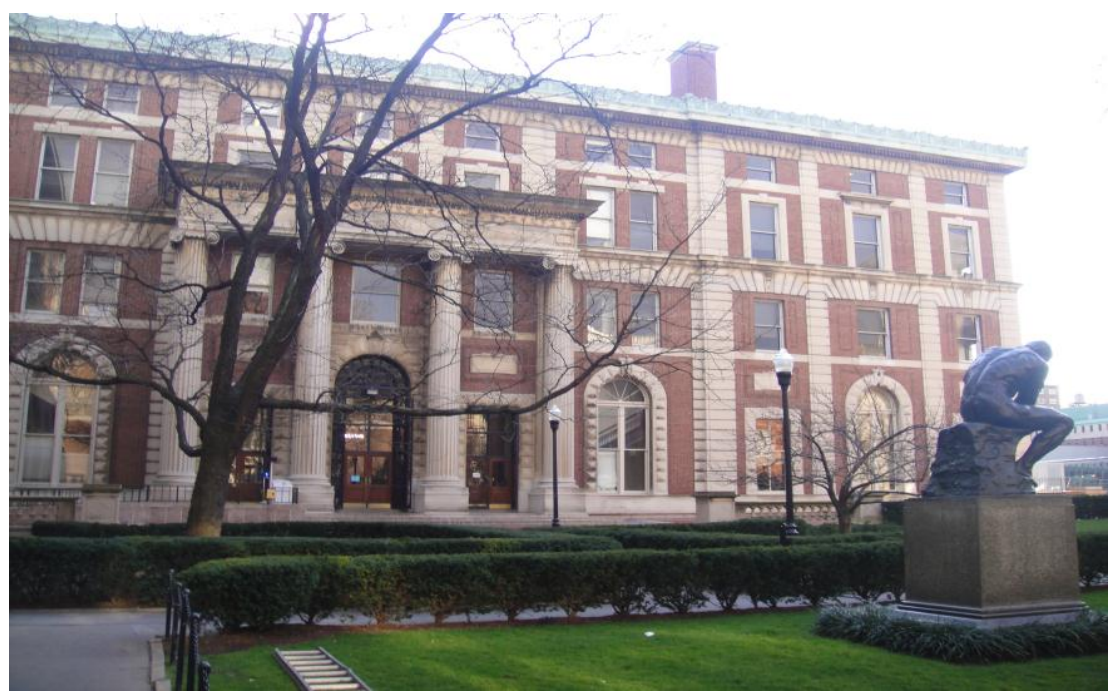

\section{Principais obras de Edward Said}

Beginnings: Intention and Method. New York: Columbia University, 1985.
The World, the Text, and the Critic. New York: Harvard University Press, 1983.
Elaborações Musicais. Trad. Hamilton dos Santos. São Paulo: Imago, 1991.
Cultura e imperialismo. Trad. Denise Bottmann. São Paulo: Companhia das Letras,
1995. $\quad$ Reflexão sobre o Exílio e Outros Ensaios. Trad. Pedro Maia Soares. São Paulo:
Companhia das Letras, 2003.
Paralelos e Paradoxos: reflexões sobre música e sociedade. Tradução de Denise
Bottmann. São Paulo: Companhia das Letras, 2003.
Cultura e politica. Trad. Luiz Bernardo Pericás. São Paulo: Editorial Boitempo, 2003.
Fora do lugar: Memórias. Trad. José Geraldo Couto. São Paulo: Companhia das Letras,
Freud e os não europeus. São Paulo: Boitempo, 2004.
Representações do intelectual. As palestras de Reith de 1993. Trad. Milton Hatoum. São
Paulo: Companhia das Letras, 2005.
Orientalismo: o oriente como invenção do ocidente. Trad. Rosaura Eichenberg. São Paulo:
Comprindo o Islã. Tradução de Bárbara Duarte. Rio de Janeiro: Ediouro, 2007.


das Letras, 2007.

Estilo tardío. Trad. Samuel Titan Junior. São Paulo: Companhia das Letras, 2009. 